\title{
Role Of Consultancy In Engineering Education
}

\author{
Nalina. ${ }^{1}$, P. Jayarekha ${ }^{2}$ \\ 1,2 Department of ISE \\ ${ }^{1,2}$ BMS College of Engineering Bangalore, India \\ 1nalinav.ise@bmsce.ac.in, ${ }^{2}$ ayarekha.ise@bmsce.ac.in
}

\begin{abstract}
Consultancy by an engineering faculty member of an institution undertakes consulting assignments to provide professional or technical solutions to specific fields. Consulting is providing an opportunity for the engineering faculty to share their insights for the real world problems. It is a dynamic learning process with respect to students and faculty as it increases the teaching and research activities. In this paper we discuss about the need for consultancy in engineering education with faculty contribution towards consultancy and advantages of consultancy to institutions. Balance the workload of the faculty consulting with the responsibilities of academics defined by the universities.
\end{abstract}

Keywords-Academic Consulting, Consultancy, Engineering Consultancy, Faculty Consulting;

\section{Nalina.V}

Department of ISE

BMS College of Engineering Bangalore, India

nalinav.ise@bmsce.ac.in

\section{Introduction}

Consulting by a faculty member of a university involves providing a professional or technical service to benefit a third party. Consultancy is well recognized as an effective way for universities to share their knowledge and expertise. Faculty consulting is to provide expertise solutions for organizations benefit, which helps to gain real time experience and also compensation. The aim of consultancy was to bridge the gap between industry and institutions to provide supported solutions to industries and other organizations.

Universities have different policies on faculty consulting with limit of faculty member's time which is spent on consulting to avoid the conflict of interest between the institution and the consulting firm which we will discuss in the paper.

Consulting will also help faculty to innovate and get expertise in some of the areas of their interest. This will also give recognition to the institute to showcase their knowledge and expertise of the faculty members.

Engineering consultancy is playing prominent role serving in all stages of the development process from definition to production and taking the individual responsibility for those operations.

The objectives of consultancies are to provide the technical support to industries and in-turn promotes research and develops technology. It also promotes 
the Seminars and Workshops for effective sharing of knowledge, Procurement of the required equipments for testing and arranging for servicing of equipments to keep in good condition.

\section{Need For Consultancy in Engineering Education}

\section{A. Need for Engineering Consultancy}

The need for engineering consultancy is demanding with the new technologies developing and the resource crunch across the industries to get solutions quickly delivered. Both engineering students and faculties benefit in developing the consulting relationships with the industries. This will give a tremendous experience which will empower their knowledge and enhance other technology areas.

Students will get benefit of learning it real time and have through knowledge which will help them choose a domain of their interest at the college level. This will give more credibility, research support and compensation.

\section{B. Faculty Contribution}

The faculty members should maintain a discipline that enables the use of opportunities fairly without disturbing their teaching and other university tasks involved. Faculty consulting should seek opportunities which will help their career growth and develop new technologies of their interest. Faculty will get more awareness on skills industry is demanding for new graduates. Faculty members will have more potential to suggest on the curriculum changes.

When involving the faculty members should clearly understand the requirements before committing because projects require a general area of expertise in the less-defined research activity or the specific research area. There are various sources to get started with consulting activities like former advisors; former students and friends can be good sources.

The training to the engineering faculty must be provided with a sound grounding in the theoretical aspects and the skills along with ability to solve problems. It must also provide students with a basic grasp and understanding of practical skills. Successful execution depends on the expertise and the communication with client which allow the professional engineer to operate effectively in a dynamic work environment.

Faculty should clearly get informed on conditions and other legal issues with respect to confidentiality and patent rights.

\section{Advantages of Consultancy to Institutes}

The Institutions will get the maximum gain with faculty consulting by retaining the talent pool which is continuously developing the advanced skills and sharing that knowledge with the students. Even the research effort to be borne by the institute is minimized and will get good credibility. In the long run developing such a healthy relationship between them will give a benefit in terms of placement to students and solving the real time critical problems.

Consultancy will ensure the relevance of the existing expertise and offers the opportunity of putting research into practice. The faculty can use the application examples for real time research and teaching.

\section{Literature Survey}

Relationship between institution and industry will help experienced and a new faculty member to gain much from consultancy. So that faculty gets excellent ideas, problems and extra money.

Faculty consultancy provides more confident for the research activities, additional income and help students for better job opportunities [6]. (Mr. Hau Lee)

Perkmann et al. [1] suggests in is paper that academic consulting is practiced in different forms and their impact on universities and industry

Nabil Amara et al. [2] addresses by differentiating between three forms of academic consulting.

1) Consulting with revenue-driven this generates income opportunities.

2) Non revenue-driven which will give technical support to help companies to resolve their technical problems without getting money.

3) Consulting providing the expertise or technical support for helping government organizations to resolve their technical problem without getting 
money.

Boyer et al. [3] describes the Faculty members who consult teach as many courses and devote much of their time to teaching, research and departmental in turn institutional activities are better than their peers who do not consult

Rebne et al. [4] describes that Consulting will make the faculty to act on their own with motivation from personal income opportunities

Meyer et al. [5] gives evidences about consulting which is widely practiced to provide industry and university interaction.

Lee [6] gives some ideas to new faculties who want to do consulting

1) Abide by university regulations and make sure the work does not interfere with teaching and research.

2) Choose subjects within their areas of expertise and interests.

3) Set up guidelines for pricing (e.g., travel time, teaching, initial meetings) but be prepared to be flexible if needed.

4) Always look for teaching and other scholarship opportunities through such engagements.

5) Spell out clearly the terms of confidentiality and publication rights.

6) Work with people who have strong interests in the success of the project.

\section{Faculty Consulting - Issues, Policies}

The main point concerning for faculty consulting is the relationship of the faculty to the college or university that employ them.

Two aspects to be considered for a faculty consulting would be issues and polices involved with consultancy.

\section{A. Issues associated with Consultancy}

Below are some of the issues that are seen in faculty consultancy.

1) The faculty consulting will be sometimes disturbing the teaching environment like having fewer interactions with students and less time for the curriculum syllabus development.

2) The clients may keep the application results proprietary in case of paid consulting but academic world focus on making freely available to the public which is contrary.

3) The management of the institutions sometimes arise concern regarding the usage of college resources for the personal activity such as office space, computers. Involvement of students should also be monitored to find out whether its valuable internship for their future career prospects.

4) Liability concerns should be taken care before accepting the activity. The consultant may go for insurance for personal liability if any incurred for the consulting activity.

\section{B. Policies}

The management should strictly publish the policies and procedures for faculty consulting with outside clients.

These policies are then incorporated into faculty employment contracts. Usually only full-time faculty will have provision for consulting. These policies will be subject to varying requirements by the college and universities. Below are some of the policies by the institutions.

1) Provision for consultancy should be out of the term time.

2) The staff time considered for consultancy should be less than $5 \%$.

3) The resources utilization should be clearly get approved by the concered.

4) Any conflict of interest arising should be immedietly get notified with the Head of faculty.

5) Funds received from consulting should be shared for using the resources and other administration costs.

\section{Statistics of Faculty who Consult}

The statistics from the National Survey of Post Secondary Faculty (NSOPF99) shows higher degree of faculty at private institutions than the faculty at the public institutions, 30 and 14 percent respectively. The income earning also varies based on the discipline of faculty. The income percentage will be between 33 percent for engineering faculty and half of that in humanities. Gender, age and race also differentiate the consultant faculty percentage. Men will have 23 percent compared to 17 percent in women. Faculty group aged above 35 earn more income than those below age group of 35. Age group between 55 and 59 
earn highest percentage. Consulting income of faculty from Asian region are only 13 percent compared to African Americans of 18 percent, 19 percent for Hispanics and 21 percent for whites. It is also proves that faculty with high-income (with base salaries $\$ 25 \mathrm{~K}$ to $\$ 40 \mathrm{~K}$ ) have more percentage that is 34 percent of consulting than those have less-income (with base salaries $\$ 25 \mathrm{~K}$ to $\$ 40 \mathrm{~K}$ ) of 15 percent of consulting. The opportunities are considered to be more for the older and much experienced faculty in their field [7].

\section{Conclusion}

Consultancy supports in bridging the gap between the industry and the universities by providing dynamic learning opportunities for both students and faculty by solving the real world problems. The colleges and universities may have to take up the issues related to consultancy and should frame the policies. These policies must support the faculty to get involved in consultancy without disturbing the regular academic work. It should provide a scope for the contribution by the faculty members to showcase their expertise and capabilities.

\section{Acknowledgment}

The author would like to acknowledge and thank to the Technical Education Quality Improvement Programme [TEQIP]-2 and SPFU [State Project Facilitation Unit] Karnataka for supporting the work.

\section{References}

[1] Perkmann, M. Walsh, K. 2008. "Engaging the scholar: three types of academic consulting and their impact on universities and industry", Research Policy, 37, pp.1884-1891.

[2] Nabil Amara and Rejean Landry. "Faculty Consultant: Quantitative evidence on a traditional government-industry-university linkage" 8th International Triple Helix Conference on University-Government-Industry,pp. 2-25.

[3] Boyer, C.M. Lewis, D. R. 1984. "Faculty consulting: responsibility or promiscuity?" The Journal of Higher Education, 55(5), pp. 637-659.

[4] Rebne, D., 1989. "Faculty consulting and scientific knowledge - a traditional university industry linkage".Educational Administration Quarterly, 25(4), pp. 337-357.

[5] Meyer-Krahmer, F., Schmoch, U., 1998. Sciencebased technologies: university-industry interactions in four fields. Research Policy 27 (8), pp. 835-851.

[6] Reis, Richard M. "When Faculty Consulting Helps -- and When It Hurts -- Your Career", The Chronicle of Higher Education, October 22, 1999, retrieved on September 24, 2011.

[7]http://education.stateuniversity.com/pages/1967/F aculty-Consulting.html. 